\title{
Aesthetic Unit-Based Reconstruction of Facial Defects with Local Flaps after Surgical Excision of Basal Cell Carcinoma
}

\author{
AHMED A.A. ALI, M.D. \\ The Department of Plastic Surgery, Faculty of Medicine, South Valley University
}

\begin{abstract}
Background: Basal cell carcinoma (BCC) represents the most common type of facial skin cancer in Middle East and Egypt. It rarely metastasizes, but because of its locally destructive nature, it can cause high morbidity. Reconstruction by local flap after surgical excision depends on the size of the defect and the affected facial aesthetic unit.
\end{abstract}

Aim: To reveal the prevalence of facial BCC, relation of its site to facial aesthetic units and type of local flaps used for reconstruction per units.

Patients and Methods: A retrospective study was conducted on 80 patients with facial BCC that admitted to the outpatient clinic, Plastic Surgery Department, Qena University Hospital from June 2018 to May 2020 (2 years duration). Only earlystage and primary tumors were included. Statistical analysis: Data was analyzed using the Statistical Package for Social Sciences (SPSS) version 24. A $p$-value $<0.05$ was considered significant.

Results: 80 patients with facial basal cell carcinoma (BCC) were collected from medical records. $45(56.25 \%)$ patients were males and $35(43.75 \%)$ patients were females $(\mathrm{M}: \mathrm{F}=$ 1.3:1). Ages ranged from 52-78 years old $(\mathrm{SD}=65 \pm 13)$. Nodular subtype was the most common clinical type of BCC and presented in $45(56.25 \%)$ patients. Nasal unit was the most common site in $18(22.5 \%)$ patients. The most random flap applied was the rhomboid (Limberg) flap in 15 cases. The most axial flap used was the nasolabial flap in 9 cases. Complications (6 cases, $7.5 \%$ ) included: Wound dehiscence in 3 cases, infection in 2 cases and skin slough in 1 case. The SCAR scale score result ranged from 0-2 score.

Conclusion: Facial defects reconstruction after surgery for basal cell carcinoma is a complex endeavor that requires careful consideration. There are many different local flaps available depending on the particular facial subunit that requires reconstruction. Careful recognition of the principles of the facial subunits will equip the surgeon to achieve the best possible functional and aesthetic outcomes.

Key Words: Facial defects - Local flaps - Basal cell carcinoma.

\section{INTRODUCTION}

Skin cancer is the most common type of malignancy. According to the shape of cells present in each lesion, it could be categorized as basal cell carcinoma (BCC) (77\%), squamous cell carcinoma (SCC) (20\%), malignant melanoma (MM) (3\%), and rare adnexal tumors arising from the skin $(<1 \%)$. The head and neck are the most affected region and accounting for $85 \%$ of $\mathrm{BCC}$ and $75 \%$ of SCC [1].

$\mathrm{BCC}$ is the most frequent type of skin cancer. Because of its locally destructive nature, it seldom metastasizes or causes death, but it can cause high morbidity. As regards to the high prevalence of $\mathrm{BCC}$, we can better recognize its characteristics, pathogenesis, clinical, and histopathological features [2].

The determination that $\mathrm{BCC}$ occurs primarily on sun-exposed sites and that sun protection can minimize its occurrence provides indirect but critical evidence for the importance of ambient solar radiation. Sunburns and intermittent heavy UV exposure at any age tend to increase the risk of BCC. On the other hand, cumulative long-term UV exposure, increase the risk of developing SCC [3].

Populations living in geographic regions with latitudes nearer to the equator have recorded higher rates of $\mathrm{BCC}$ than other populations [4]. BCC is more common in people above the age of 50, but less is recognized about its occurrence in people below the age of 40 [5].

Several studies have investigated the link between age, gender and anatomical distribution in regard to various $\mathrm{BCC}$ variants, such as nodular, superficial, and morphea-form BCC. According to recent research, BCC's anatomical site clarifies the development of specific subtypes. Although, more studies are required to fully understand these connections [6].

Surgical excision is the most curable line of treatment for primary $\mathrm{BCC}$ and has become the 
standard line of therapy for longtime. A 3-7 millimeters excision margin is typically beneficial. Reconstruction with local flaps rather than direct closure is recommended for wound closure in BCC cases on the face, particularly in medium-sized defects [7].

Concept of the facial aesthetic units should be followed to achieve optimum functional and cosmetic outcomes, and multiple staged procedures and revisions are often needed. For choosing a reconstructive plan that both retains facial function and maximizes cosmetic outcomes, a detailed understanding of facial units and their subunits is required [8].

The main principles included: (1) Skin closure under minimum tension, (2) Replacing "like with like", (3) Maintaining major anatomical structures (e.g., ear, nose, eyebrow), and (4) Scar position corresponding to functional and aesthetic units are all the key concepts for optimum closure [8].

The aim of the study was to detail the epidemiology of basal cell carcinoma, relation of its site to facial aesthetic units, and the type of local flap used per aesthetic unit for reconstruction following surgical excision. Also, to reveal surgical and patient-reported outcomes.

\section{PATIENTS AND METHODS}

Study design: A retrospective study was conveyed on 80 patients had facial basal cell carcinoma (BCC) that enrolled to the outpatient clinic, Plastic Surgery Department, Qena University Hospital from June 2018 to May 2020 (2 years duration).

Study population: Inclusion criteria: Patients had early-stage and primary tumors that were mobile or not attached to the underlying bone or cartilage and were curable by surgical resection.

Exclusion criteria: Patients had late-stage, neglected, recurrent tumors, fixed tumors or infiltrated the underlying bone or cartilage and were not curable by surgical resection.

Approval and consent: The study was approved by our Faculty Ethical Committee for research in human studies. Informed consent and written releases from patients for their photos were signed.

Data collection: Data was gathered from medical records that included the following parameters: Age, sex, site of tumor, type of tumor, defect size, type of flap, anesthesia type, follow-up and com- plications. Site of tumors was divided into 6 groups regrading to the principle of facial aesthetic units (forehead, nasal, periorbital, cheek, perioral and periauricular) and their subunits. Clinical types of BCC were classified based on clinical examination into 5 subtypes: Nodular, superficial, pigmented, morphea like and cystic.

Statistical analysis: Data was analyzed using the Statistical Package for Social Sciences (SPSS) version 24 . A $p$-value $<0.05$ was considered significant.

Methods of evaluation: Cosmetic outcomes were evaluated by the Scar Cosmesis Assessment and Rating (SCAR) scale numbered between 0 and 15 ; the best is score 0 and the worst is score 15 ; Table (1).

Table (1): The Scar Cosmesis Assessment and Rating (SCAR) scale.

\begin{tabular}{|c|c|c|}
\hline Parameter & Descriptor & Score \\
\hline & Clinician questions & \\
\hline \multirow[t]{5}{*}{ Scar spread } & None/near invisible & 0 \\
\hline & Pencil-thin line & 1 \\
\hline & $\begin{array}{l}\text { Mild spread, noticeable on close } \\
\text { inspection }\end{array}$ & 2 \\
\hline & Moderate spread, obvious scarring & 3 \\
\hline & Severe spread & 4 \\
\hline \multirow[t]{4}{*}{ Erythema } & None & 0 \\
\hline & $\begin{array}{l}\text { Light pink, some telangiectasias } \\
\text { may be present }\end{array}$ & 1 \\
\hline & $\begin{array}{l}\text { Red, many telangiectasias may be } \\
\text { present }\end{array}$ & 2 \\
\hline & Deep red or purple & 3 \\
\hline \multirow[t]{2}{*}{ Dyspigmentation } & Absent & 0 \\
\hline & Present & 1 \\
\hline \multirow[t]{2}{*}{ Suture marks } & Absent & 0 \\
\hline & Present & 1 \\
\hline \multirow{4}{*}{$\begin{array}{l}\text { Hypertrophy/ } \\
\text { atrophy }\end{array}$} & None & 0 \\
\hline & $\begin{array}{l}\text { Mild: Palpable, barely visible } \\
\text { hypertrophy or atrophy }\end{array}$ & 1 \\
\hline & $\begin{array}{l}\text { Moderate: Clearly visible } \\
\text { hypertrophy or atrophy }\end{array}$ & 2 \\
\hline & $\begin{array}{l}\text { Severe: Marked hypertrophy or } \\
\text { atrophy or keloid formation }\end{array}$ & 3 \\
\hline \multirow{3}{*}{$\begin{array}{l}\text { Overall } \\
\text { impression }\end{array}$} & Desirable scar & 0 \\
\hline & Undesirable scar & 1 \\
\hline & Patient questions & \\
\hline \multirow[t]{2}{*}{ Itch } & No & 0 \\
\hline & Yes & 1 \\
\hline \multirow[t]{2}{*}{ Pain } & No & 0 \\
\hline & Yes & 1 \\
\hline
\end{tabular}




\section{RESULTS}

Eighty patients with facial basal cell carcinoma (BCC) were collected; Table (2). Of these cases, $45(56.25 \%)$ patients were males and $35(43.75 \%)$ patients were females $(\mathrm{M}: \mathrm{F}=1.3: 1)$. Their ages were ranged from 52-78 years old $(\mathrm{SD}=65 \pm 13)$. The most commonly presented clinical type was the nodular subtype in $45(56.25 \%)$ patients, then the pigmented subtype in $15(18.75 \%)$ patients, the superficial subtype in $13(16.25 \%)$ patients and lastly the morphea-like subtype in $7(8.75 \%)$ patients, none of them had the cystic subtype.

Table (2): Demographic and clinical characteristics of the study population $(\mathrm{N}=80)$.

\begin{tabular}{|c|c|c|}
\hline Parameter & No. of cases & Percentage \\
\hline \multicolumn{3}{|l|}{ Gender: } \\
\hline - Male & 45 & 56.25 \\
\hline - Female & 35 & 43.75 \\
\hline \multicolumn{3}{|l|}{ Clinical type: } \\
\hline - Nodular & 45 & 56.25 \\
\hline • Pigmented & 15 & 18.75 \\
\hline - Superficial & 13 & 16.25 \\
\hline - Morphea like & 7 & 8.75 \\
\hline - Cystic & 0 & 0 \\
\hline \multicolumn{3}{|l|}{ Facial subunit: } \\
\hline • Nasal & 18 & 22.5 \\
\hline • Cheek & 16 & 20 \\
\hline - Forehead & 14 & 17.5 \\
\hline - Periorbital & 12 & 15 \\
\hline - Perioral & 10 & 12.5 \\
\hline - Periauricular & 5 & 6.25 \\
\hline - More than one & 5 & 6.25 \\
\hline \multicolumn{3}{|l|}{ Type of flap: } \\
\hline - Random & 53 & 66.25 \\
\hline - Axial & 27 & 33.75 \\
\hline \multicolumn{3}{|l|}{ Random flap type: } \\
\hline • Rhomboid & 15 & 28.3 \\
\hline • Bilobed & 10 & 18.9 \\
\hline - V-Y advancement & 7 & 13.3 \\
\hline - Glabellar & 6 & 11.4 \\
\hline - Rotation & 5 & 9.4 \\
\hline - Cheek advancement & 4 & 7.5 \\
\hline - Transposition & 2 & 3.7 \\
\hline • Others & 4 & 7.5 \\
\hline \multicolumn{3}{|l|}{ Axial flap type: } \\
\hline • Nasolabial & 9 & 33.3 \\
\hline - Cross lip & 6 & 22.2 \\
\hline • Forehead & 5 & 18.5 \\
\hline - Dorsal nasal & 3 & 11.2 \\
\hline • Others & 4 & 14.8 \\
\hline \multicolumn{3}{|l|}{ Complications: } \\
\hline - Wound dehiscence & 3 & 3.75 \\
\hline • Infection & 2 & 2.5 \\
\hline - Skin slough & 1 & 1.25 \\
\hline - Total & 6 & 7.5 \\
\hline
\end{tabular}

The most common unit was the nose in 18 $(22.5 \%)$ patients, then the cheek in $16(20 \%)$ patients, the forehead in $14(17.5 \%)$ patients, the periorbital area in $12(15 \%)$ patients, the perioral area in $10(12.5 \%)$ patients and lastly the periauricular area in $5(6.25 \%)$ patients, and more than one subunit in $5(6.25 \%)$ patients.

Surgical excision with adequate safety margin was the standard tool of treatment. The safety margin was ranged from $3-7 \mathrm{~mm}$ (mean $5 \mathrm{~mm}$ ) in regarding to type and site of BCC. Histopathological report confirmed the clinical diagnosis. Size of the defect was ranged from $1.5 \mathrm{~cm} \times 1.5 \mathrm{~cm}$ up to $3 \times 4 \mathrm{~cm}$ in diameter $($ mean $=2.25 \mathrm{~cm} \mathrm{x} 2.75 \mathrm{~cm})$. The resultant defects were reconstructed by local flaps (random and axial). Random flaps were used in 53 cases $(66.25 \%)$, while 27 cases $(33.75 \%)$ were covered by axial flaps.

As a random flap, the rhomboid (Limberg) flap was mostly used in fifteen cases, then the bilobed flap in ten cases, V-Y advancement in seven cases, glabellar in six cases, and rotation in five cases. The nasolabial flap was most commonly applied axial flap in nine cases, then by the cross lip (Abbe - Estlander) flap in six cases, forehead flap in five cases, and dorsal nasal flap in three cases.

There were fourteen forehead defects included: Three defects in central forehead, five defects in lateral forehead and six cases in temple. Reconstruction with rotation flaps were done in five cases and rhomboid flaps in three cases; some cases are shown in Fig. (1), transposition flaps in two cases, $\mathrm{H}$-flap in three cases and M-flap in one case.

There were eighteen nasal defects: Five defects in nasal dorsum, four defects in lateral sidewall, three nasal tip defects, three nasal alae defects, and three defects in the combined dorsum and sidewall. In five cases, these nasal defects were covered by forehead flaps (three paramedian and two island flaps), their donor sites were closed primary; some cases are shown in Fig. (2).

Nasolabial flaps were applied in four cases (two superiorly based flaps, two inferiorly based flaps); some cases are shown in Fig. (3), and dorsal nasal flaps used in three cases; some cases are shown in Fig. (4). Two cases were reconstructed by glabellar flap, two cases by bilobed flap, and two cases by rhomboid flap.

There were sixteen cheek defects: Five cases were present in the infraorbital subunit, five in the zygomatic subunit, three in the buccal subunit, two in the combined zygomatic and buccal subunits, 
and one in the mandibular subunit. In five cases, the bilobed flap was applied for coverage, followed by V-Y advancement flaps in four cases, rhomboid flap in four cases; Fig. (5), cheek advancement flap in three cases; Fig. (6), and island nasolabial in two cases; Fig. (7).
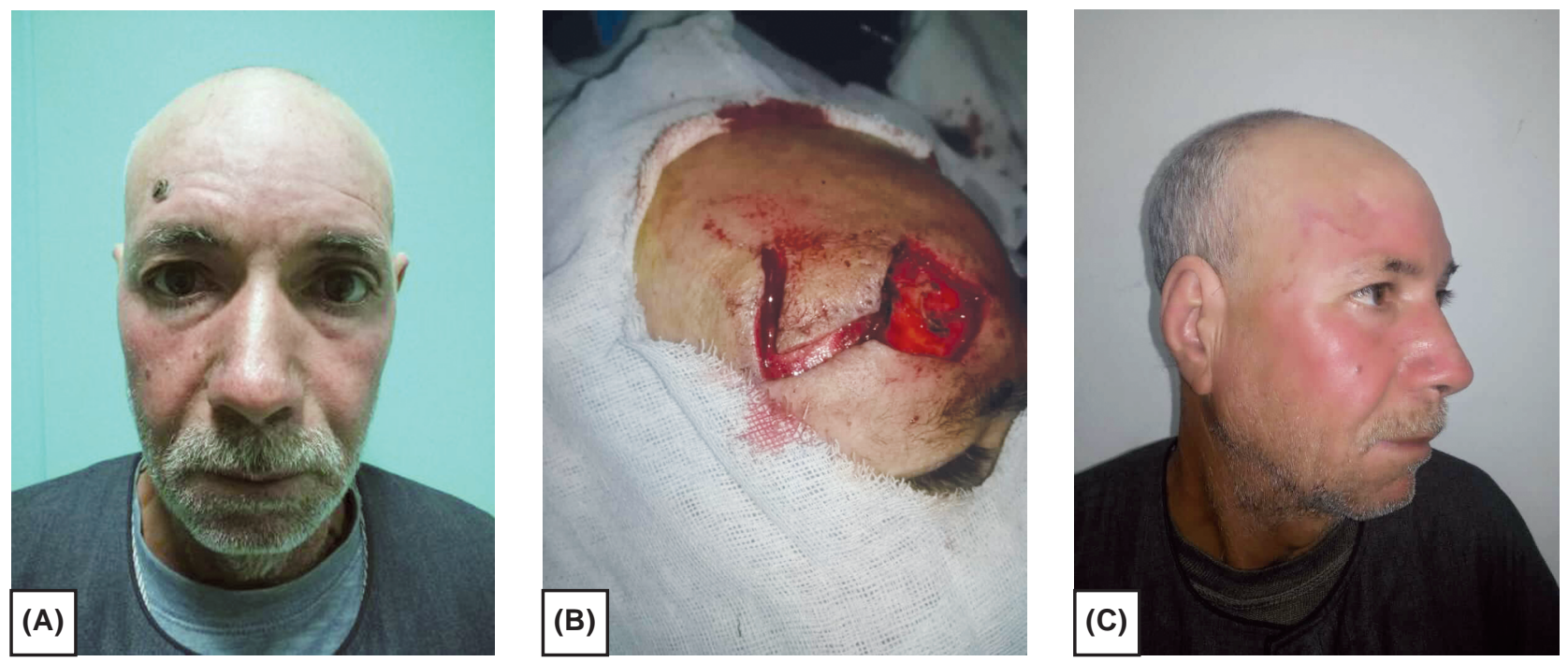

Fig. (1): Male patient with forehead BCC: (A): Pre-operative photo shows pigmented BCC at right lateral forehead, (B): Intraoperative after excision and rhomboid flap elevation, (C): Post-operative photo after 8 months.
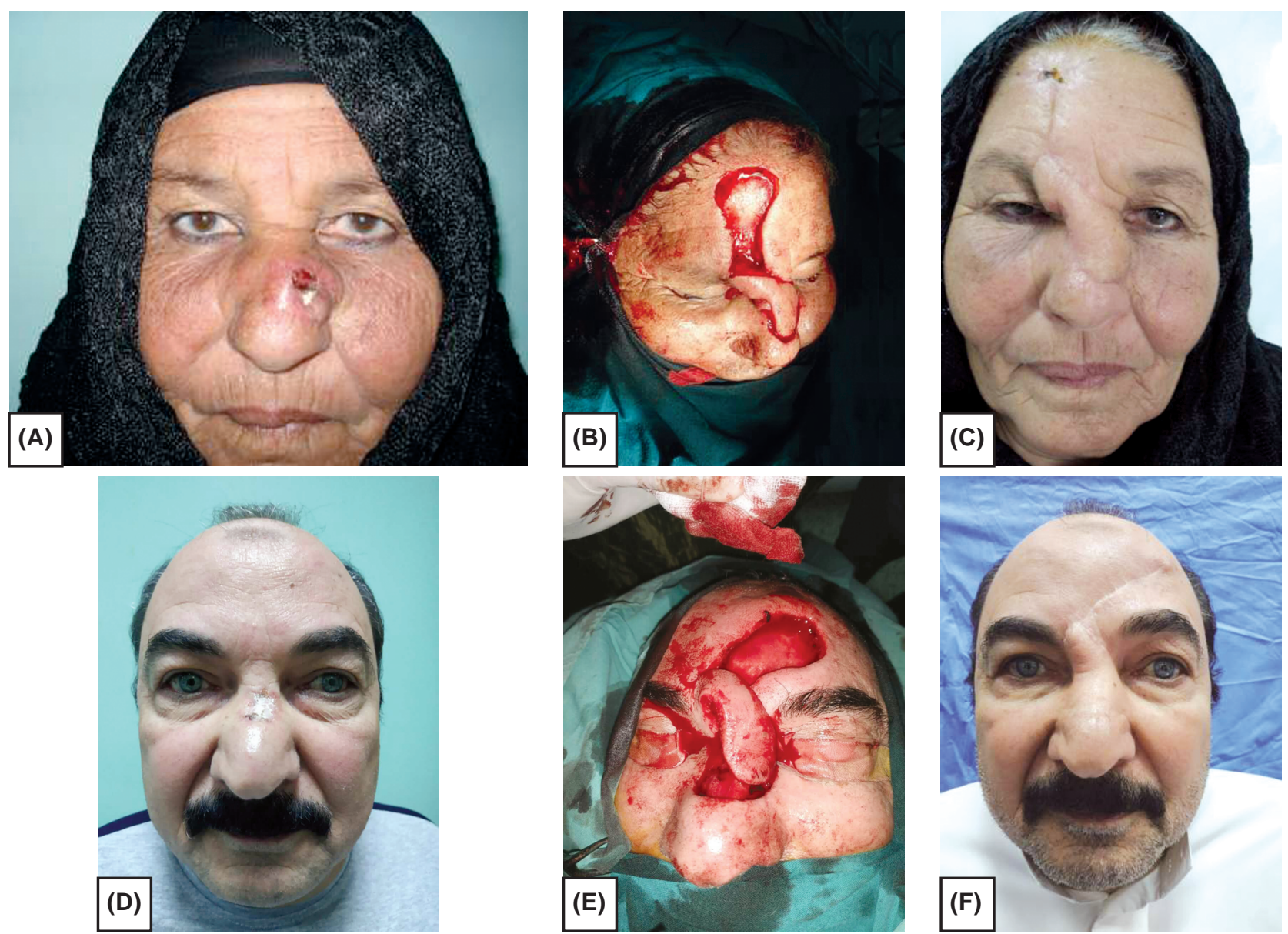

Fig. (2): Shows two cases with nasal BCC reconstructed by forehead flaps, (A-C): Female patient with nasal BCC: (A): Preoperative photo shows nodular BCC at nasal dorsum and left nasal side wall, (B): Intraoperative after lesion excision and midline forehead flap insetting, (C): Post-operative photo after 8 months. (D-F): Male patient with nasal BCC, (D): Preoperative photo shows superficial BCC at nasal dorsum, (E): Intraoperative after lesion excision and paramedian forehead flap insetting, (F): Post-operative photo after 10 months. 

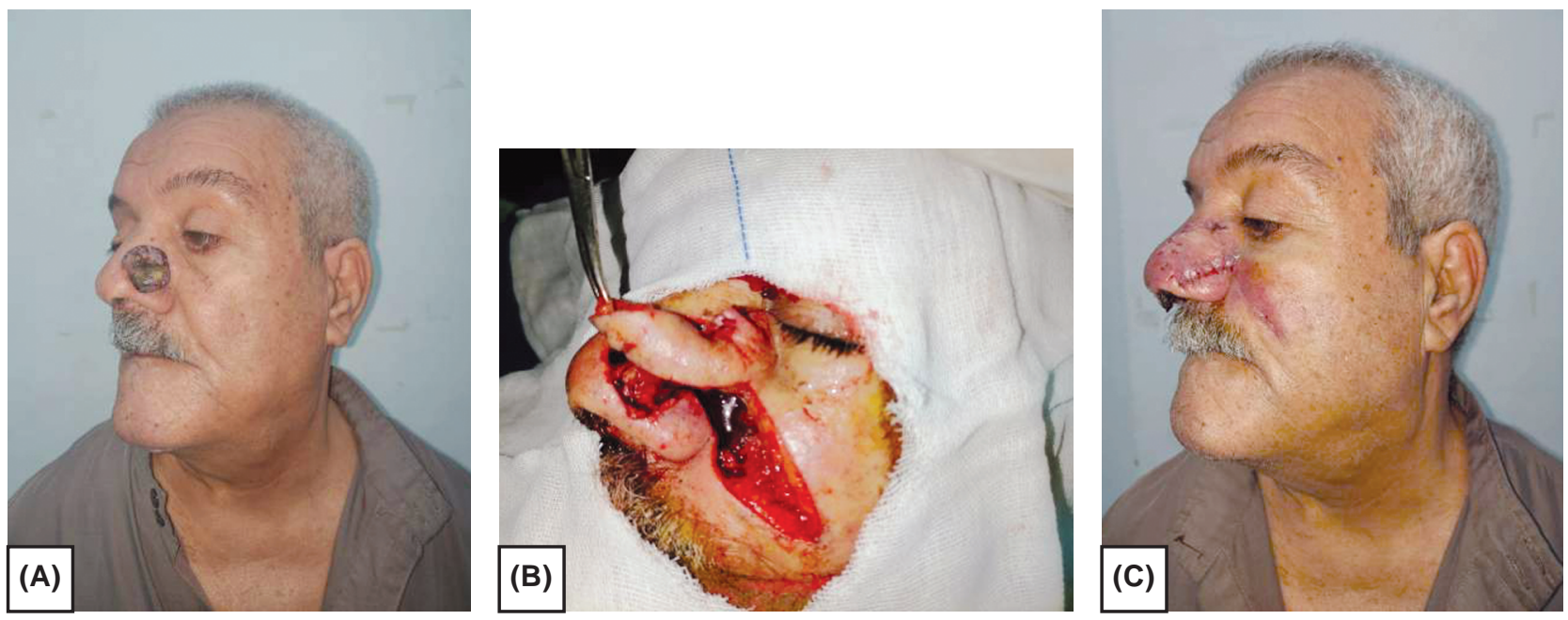

Fig. (3): Male patient with nasal BCC: (A): Pre-operative photos show pigmented BCC at nasal dorsum, left nasal side wall and small part from left ala, (B): Intraoperative after excision and superiorly based nasolabial flap elevation, (C): Postoperative photo after 2 months.
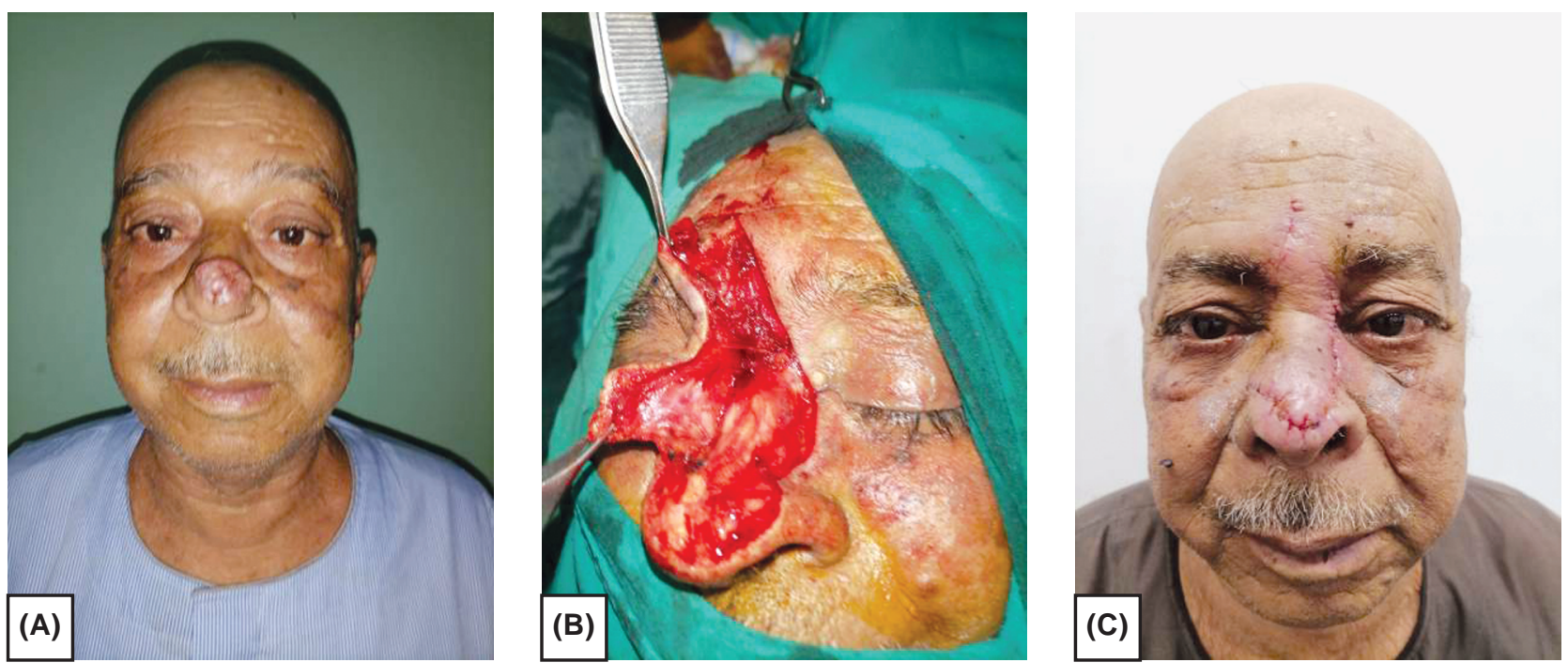

Fig. (4): Male patient with nasal BCC, (A): Pre-operative photos show nodular BCC at nasal tip, (B): Intraoperative after excision and dorsal nasal flap elevation, (C): Post-operative photo after 3 months.
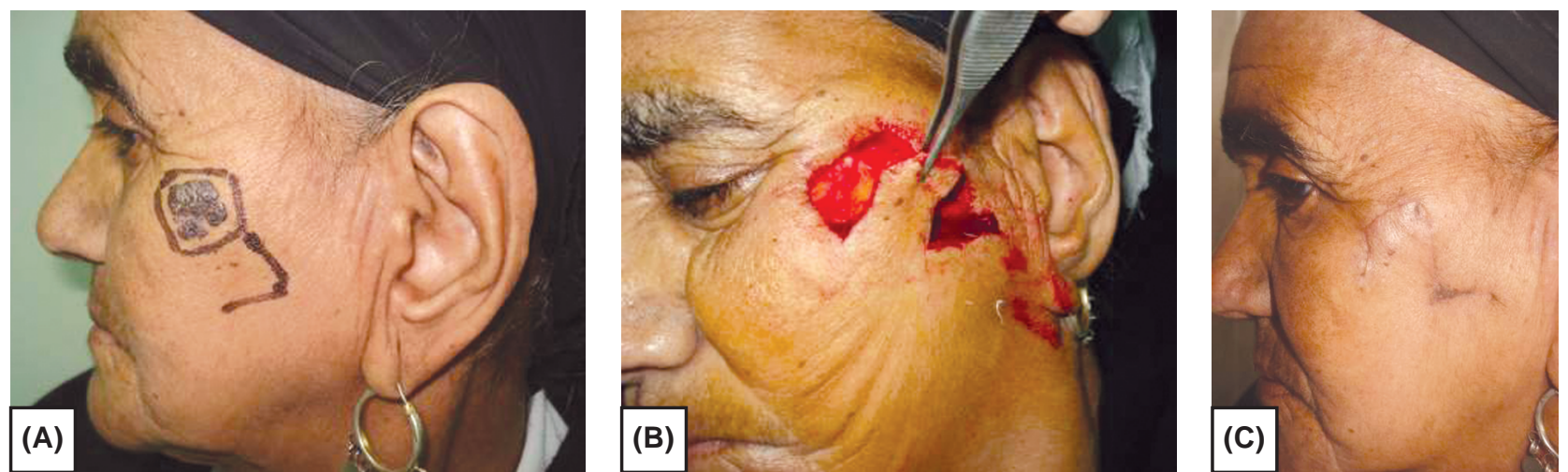

Fig. (5): Female patient with cheek BCC, (A): Pre-operative photos show pigmented BCC at left zygomatic subunit, (B): Intraoperative after excision and rhomboid flap elevation, (C): Post-operative photo after 7 months. 

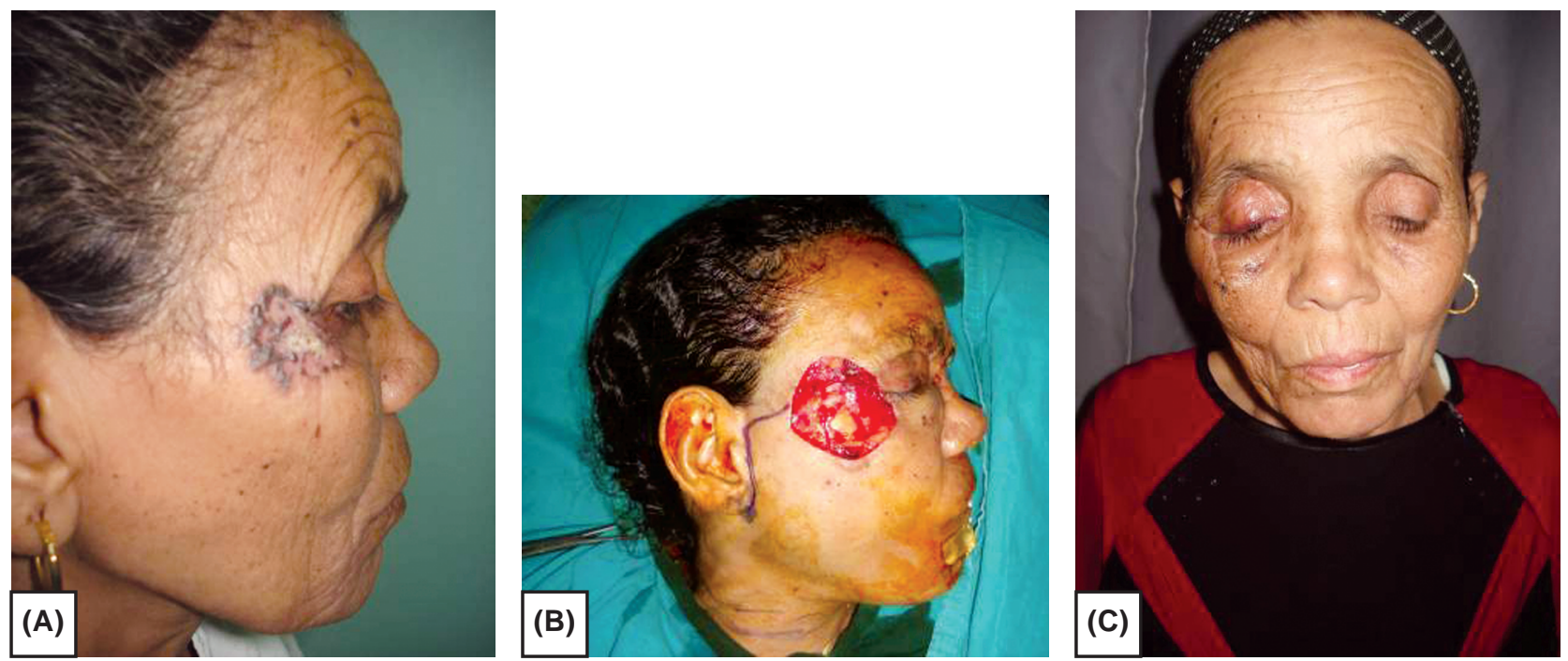

Fig. (6): Female patient with cheek BCC, (A): Pre-operative photos show pigmented BCC at right zygomatic subunit and periorbital unit, (B): Intraoperative after excision and cheek advancement flap elevation, (C): Post-operative photo after 8 months.
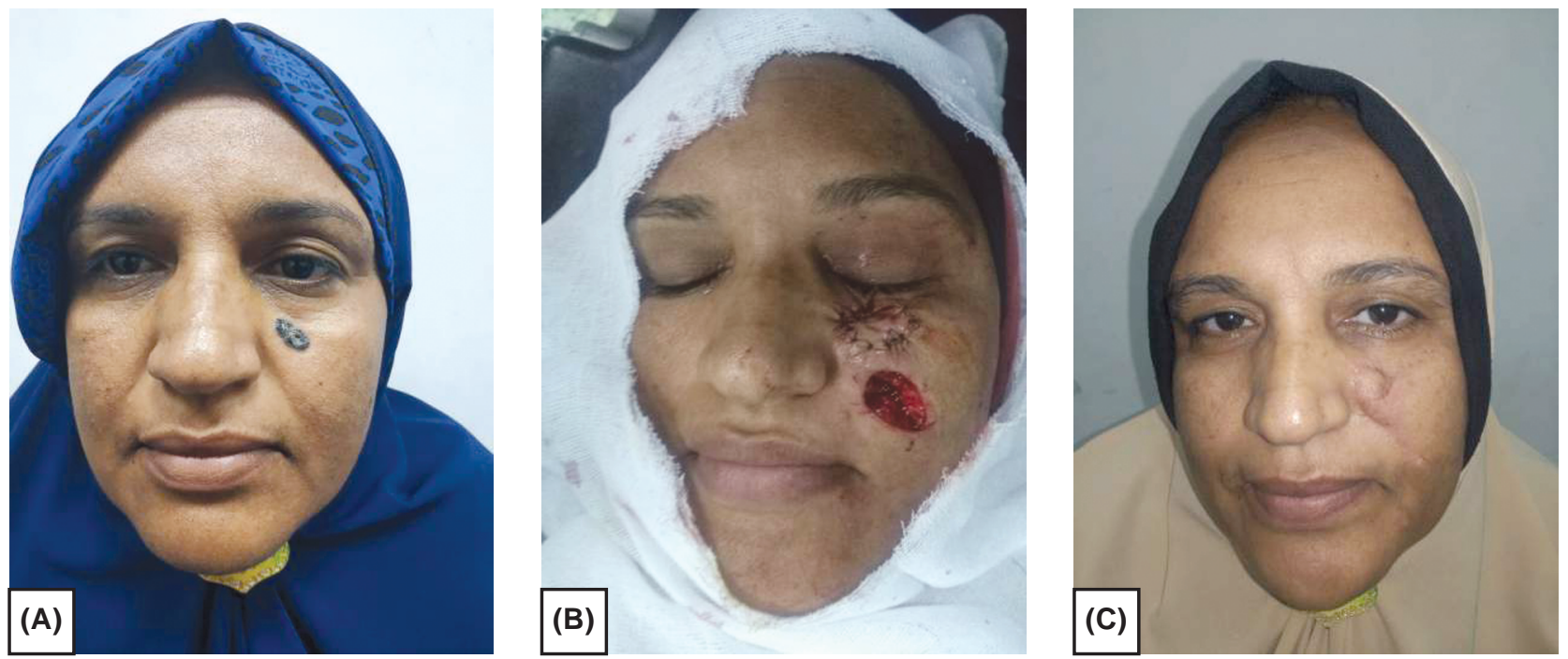

Fig. (7): Female patient with cheek BCC, (A): Pre-operative photos show pigmented BCC at left infraorbital subunit, (B): Intraoperative after excision and island nasolabial flap elevation, (C): Post-operative photo after 11 months.

In the perioral region, ten defects in the upper lip were identified: Six cases in the central lip and four cases in the lateral lip. Cross-lip flap (three cases with Abbe flap and three cases with Estlander flap) was the most common flap used, then nasolabial flap in two cases; some cases are shown in Fig. (8) and one case with unilateral Gilles fan flap; shown in Fig. (9) and Karapandzic flap in one case.
There were twelve periorbital defects: Four medial canthal defects, three lateral canthal defects, two upper eyelid defects, two lower eyelid defects, and one periorbital subunit defects. Glabellar flap was applied for medial canthal defects; some cases are shown in Fig. (10). Bilobed flap used in three cases, V-Y advancement in three cases, and rhomboid flap in two cases. 

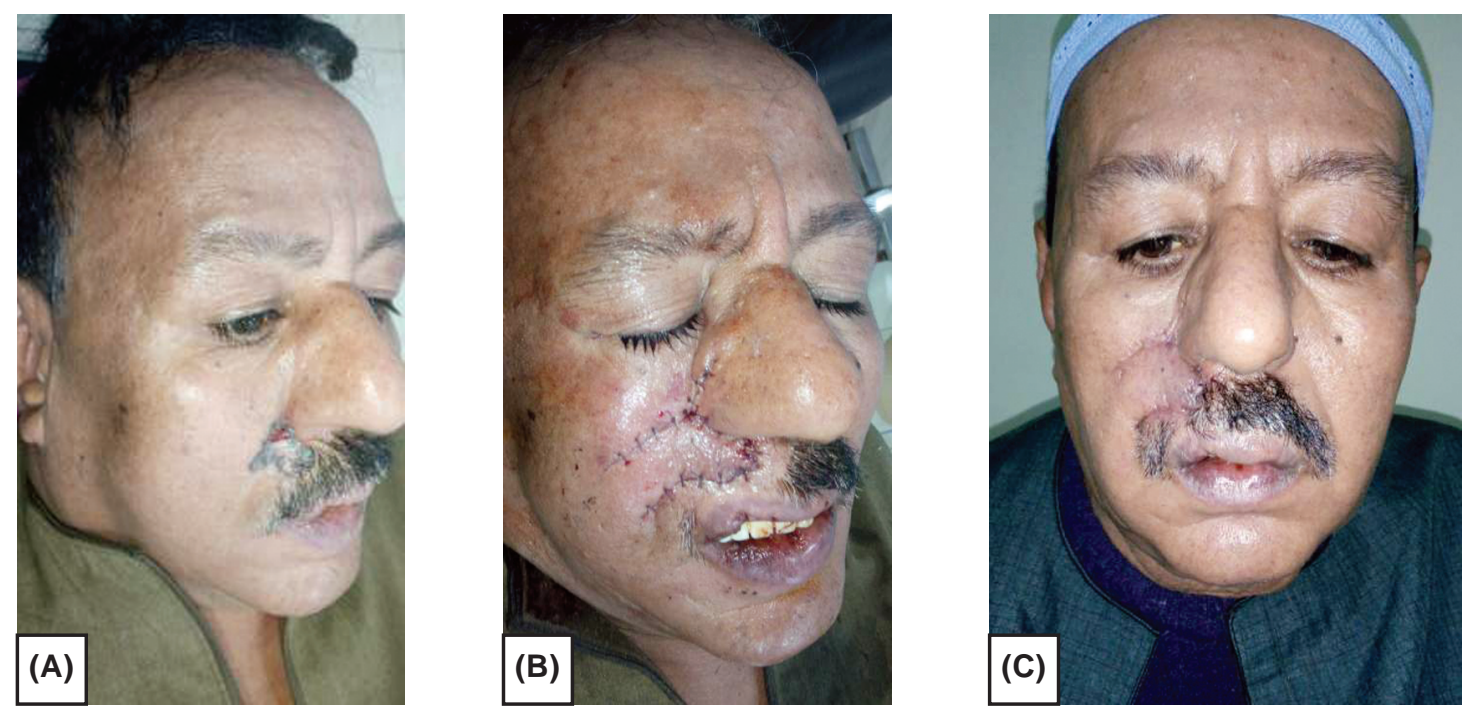

Fig. (8): Male patient with upper lip BCC, (A): Preoperative photos show pigmented BCC at right lateral upper lip subunit, (B): Intraoperative after excision and inferiorly based nasolabial flap insetting, (C): Post-operative photo after 6 months.
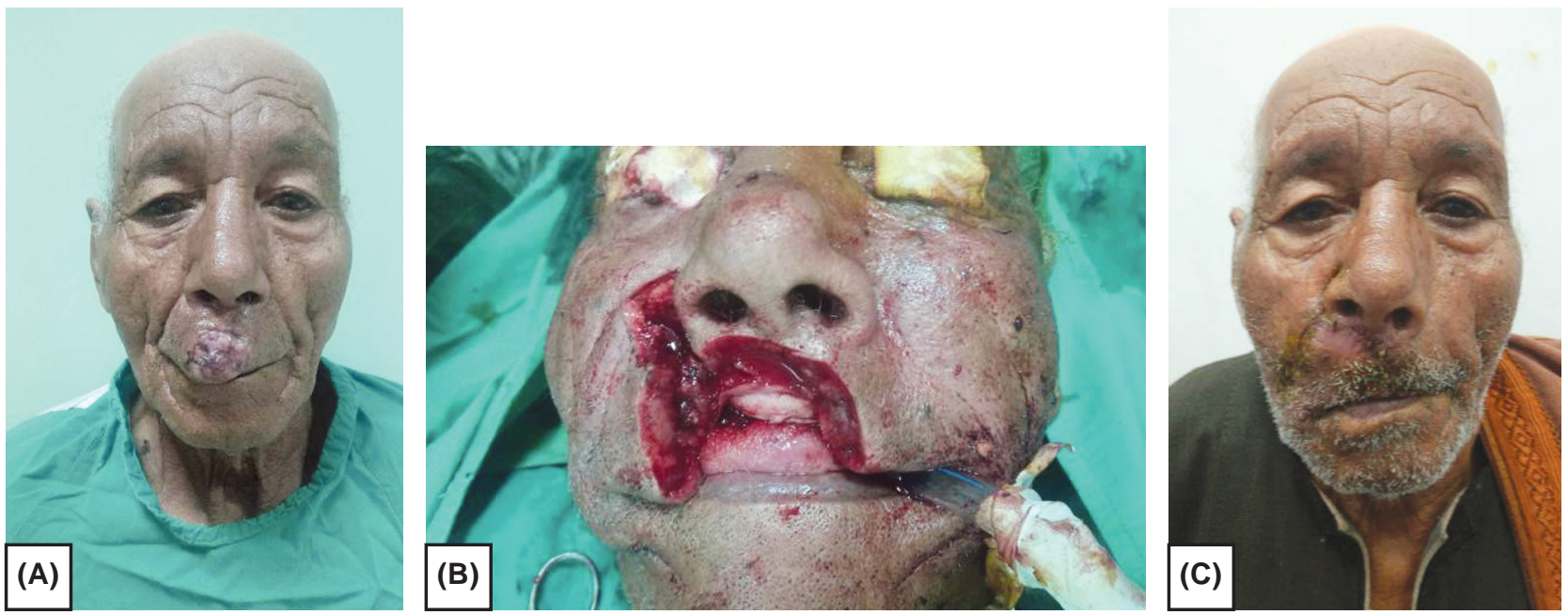

Fig. (9): Male patient with upper lip BCC, (A): Pre-operative photos show nodular BCC at central upper lip subunit, (B): Intraoperative after excision and Gilles fan flap elevation, (C): Post-operative photo after 6 months.
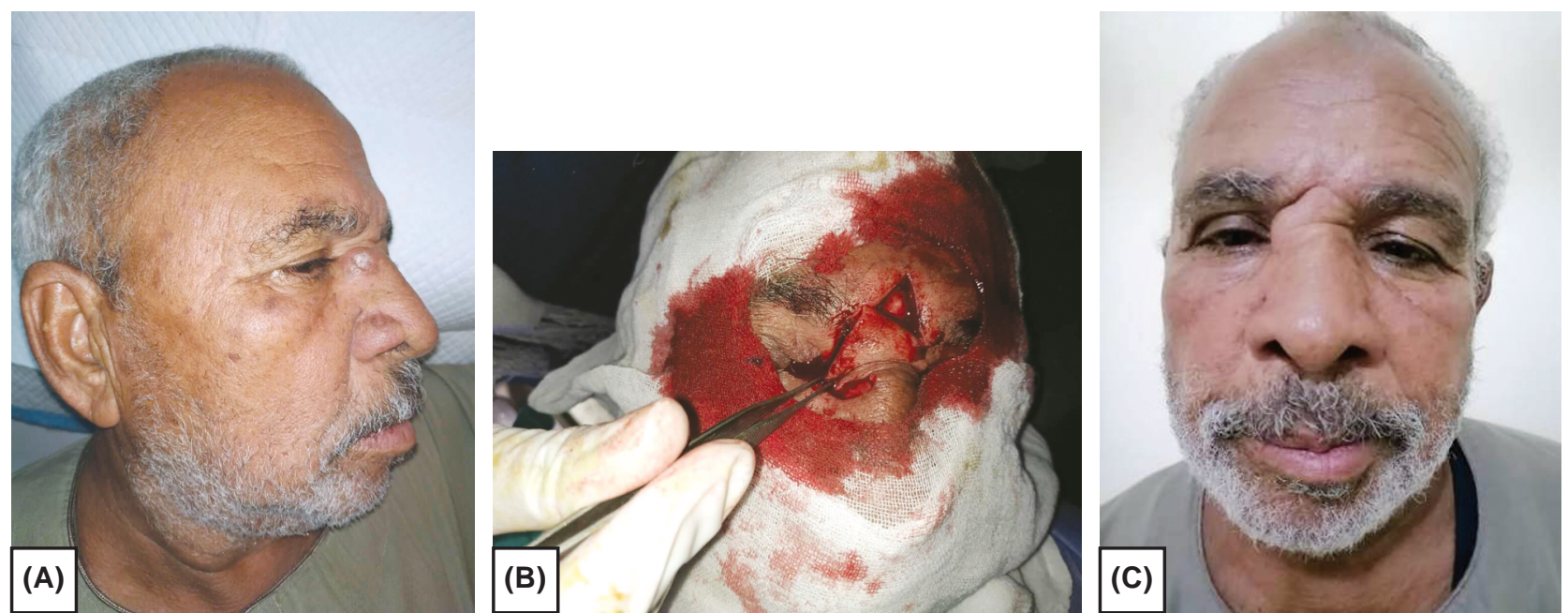

Fig. (10): Male patient with right medial canthus BCC, (A): Pre-operative photos show pigmented BCC right medial canthus subunit, (B): Intraoperative after excision and glabellar flap insetting, (C): Post-operative photo after 8 months. 
Five defects were reconstructed in the periauricular region: Three in the ear proper, reconstructed with a helical advancement flap, and two defects in the retro-auricular area, reconstructed with a rhomboid flap.

Defects affected more than one aesthetic unit in five cases: Two cases had defects in both upper lip and cheek (reconstructed by an inferiorly dependent nasolabial flap), two cases had defects in both the nasal and cheek units (reconstructed by a rhomboid flap), and one case had defects in both the infraorbital and lower eyelid (reconstructed by a rhomboid flap), and one case had defects in both the in (reconstructed by cheek advancement flap).

In seven cases, staged reconstruction was performed: Three with paramedian forehead flaps (for flap separation), three with Abbe flaps (for flap separation), and one with Karapandzic flap (for flap separation) (due to resultant microstomia).

The period of follow-up varied from 6 to 12 months. To avoid scar hyperpigmentation, patients advised to avoid sun exposure for 6 to 9 months after surgery. Complications detected in only six cases $(7.5 \%)$ : Three cases in the nasal and three cases in the cheek subunits. Wound dehiscence was the most common complication in three cases, inflammation in two cases, and skin slough in one case. Reports revealed no recurrence or incompletely excised lesion. Scores on the SCAR scale ranged from 0 to 2 .

\section{DISCUSSION}

The face is a common site for malignant skin tumors. It is cosmetically the most critical anatomic area. Therefore, malignant skin tumors of the face have a great obstacle in their diagnosis, preventing compromises between surgical treatment and cosmetic and functional outcomes [9].

A retrospective analysis was conducted on eighty patients presented with facial basal cell carcinoma was conducted. Male predominance was explained by their more outdoor activities that result in increased exposure to sunlight. This prevalence is consistent with many studies [6-9]. Choi et al., observed in a previous retrospective study that $\mathrm{BCC}$ is more common in females, with male to female ratio of $1: 1.4[10]$.

Also, BCC is more common in females than in males, according to Bertozzi et al., with a ratio of 1:0.9. Females' higher occurrence was thought to be due to their longer life expectancy [11]. The research by Mancuso et al., revealed that sex hor- mones like estrogen may play a role in skin cancer development, but this relationship has yet to be thoroughly investigated in a clinical or epidemiologic setting [12]. In this study, the ages ranged from 52 and $78(S D=65 \pm 13)$. Many researches have shown that the average age is similar $[\mathbf{1 , 3 , 5 , 6}$, 9-13].

Nodular BCC was the most reported subtype, then pigmented subtypes. This finding is close to that of Welly, who found the nodular subtype in $37(52,86 \%)$ cases and the pigmented group in 29 $(41,43 \%)$ cases [3]. Cameron et al., also, found the nodular subtype in 62.4 percent of cases in a review they conducted [13]. According to recent studies, BCC's anatomical position may favor the evaluation of specific subtypes. The head and neck are the most common sites for nodular BCCs, while the trunk is more often affected by superficial BCCs [14].

In analysis of the location of $\mathrm{BCC}$, the nose was the most commonly affected unit, followed by the cheek and the forehead. Kang et al., reported that the nose was the most common location for BCC (44 of 138 cases, or 31.9 percent) in a sample of 138 cases of BCC [1]. Welly analyzed 70 cases of facial BCC retrospectively and found that the nose was the most commonly affected unit (24 patients, 64.29 percent) [3]. In a retrospective analysis of 171 cases of BCC in the head and neck region, Janjua et al., found that $\mathrm{BCC}$ was more common in the nose (53 cases, 46.3\%) [15].

Buettner and Raasch [16] estimated the cutaneous malignant lesion incidence rate and reported that it was most frequent in the lip, orbit, and nasolabial regions. According to Kim et al., BCC first appeared on the cheek, then the periorbital region, and finally the nose [17].

In this study, local flaps were the principal method of covering the resultant defects after surgical excision. The versatility of these flaps and reliable facial vascularity, resulted in excellent esthetic results. Rhomboid (Limberg) flap was the most commonly applied random flap, then bilobed flap. Nasolabial flap was the most commonly used axial flap, then cross lip (Abbe-Estlander) flap.

There are some considerations to be detailed before nasal reconstruction: Firstly, nasal skin is mostly sebaceous in consistency. Secondly, nasal bony area is covered by very mobile skin, while the skin that covers cartilaginous area is tighter, thicker and more firmly attached. Nasal aesthetic components must be taken into account. Final scars 
should be located wherever possible along lines of relaxed skin tension [18].

Forehead flap was the most frequently performed flap for nasal coverage. It is a versatile flap and can cover all nasal defects from just tip and ala loss up to a whole nasal defect. Functional and esthetic outcomes can be obtained with this flap by constituting a nose that integrates well with other facial units [19].

Nasolabial flap was the second versatile flap for nasal reconstruction. Superiorly based flap is applied to treat nasal sidewall, ala, and tip defects, while the inferiorly based flap is applied to treat nasal floor, and columella defects. Its advantages included that: Good texture match and color, and the donor site scar is hidden in nasolabial furrow [20].

When selecting a coverage plan for cheek reconstruction, including the selection and design of local flaps, anatomical subunits of the cheek are usually the most relevant aspect to get priority. Skin color and texture of the local flap can be matched to the nearby tissue. The cheek has the unusual feature that most subunits are not protected by underlying bone, making it a primary aim in cheek reconstruction to prevent changes in adjacent structures [21].

Bilobed flap was the most frequently used flap for cheek reconstruction, then rhomboid (Limberg) flap and V-Y advancement flap. Majority of cheek defects were small to medium in size, making these local random flaps ideal for reconstruction.

Forehead reconstruction is unique as it has different anatomical subunits. In central forehead defects, H-flap and M-flap were the preferred choice in reconstruction. While in lateral forehead and temple defects, rhomboid (Limberg), rotational and transposition flaps were the suitable options.

Periorbital reconstruction had obstacles after excision of malignant skin tumors such as achieving symmetry, stable eyelid margin, smooth internal surfaces providing appropriate vertical and horizontal eyelid measurements for maximal function, adequate eyelid closure to avoid exposure sequelae and retaining normal tension [22]. Glabellar flap was the most common flap used for covering periocular defects, followed by bilobed flap and V-Y advancement, these flaps obtained good satisfaction.

The perioral region is a complex unit because its three-dimensional soft tissue topography and proximity to important anatomic landmarks. Addi- tionally, its relative paucity of underlying fascial or bony support can lead to adverse outcomes including soft tissue contraction and swelling. Notably, this could be prevented with application of local flaps giving a high satisfaction in functional and cosmetic outcomes, Past surgical experience of lip defect closure has included frequent use of flaps like Abbé, Gillies, and Karapandzic [23].

Periauricular lesions were treated regarding to either in ear lobe proper (reconstructed by helical advancement flap) or periauricular area (reconstructed by rhomboid flap).

The facial reconstruction of surgical defects after surgical excision of skin tumors based on facial aesthetic units is well described in the literature and recommended by various authors. Russo et al., published a guideline that specified which flap should be used in each cosmetic unit [24].

Russo et al., reported that the glabellar flap had the highest score for defects of the medial canthus of the eye. The flaps with the highest scores were the bilateral advancement flag flap or $\mathrm{H}$ flap for the forehead, the revolving-door flap for the auricle of the ear, the Mustarde flap for the infraorbital cheek, the O-Z rotation flap for the scalp, the Tenzel flap for the lower eyelid, and the island flap for the upper lip [24].

A retrospective review by van Leeuwen were performed on 202 cases with facial skin cancer. In this review, the nose was most often involved $(52.0 \%)$, followed by the periocular area $(12.9 \%)$, cheek (11.9\%), lips (7.9\%), and forehead (6.9\%), respectively. The resulting facial defects after Mohs micrographic surgery (MMS) varied in size from 5 to $200 \mathrm{~mm}$ in diameter (mean, $35.5 \mathrm{~mm}$ ). In 161 patients $(79.7 \%)$, the defect involved 1 aesthetic facial unit, and in 41 patients $(20.3 \%)$, the defect extended beyond 1 facial unit (38 patients 2 units and 3 patients 3 units) [25].

van Leeuwen reported that the most commonly flaps used for reconstruction were rotation advancement flap for forehead defect, cheek rotation advancement in periocular defects, forehead flap then bilobed and dorsal nasal flaps in nasal defects cheek rotation advancement in cheek defects, Abbe flap for upper lip defects [25].

Rao and Shende performed a retrospective analysis of 70 patients who had skin cancer in the facial area that surgically removed and then repaired using local fasciocutaneous flaps. The VY advancement flap was used on 34 patients, while the nasolabial flap was used on 24 patients, the median 
forehead flap was used on 8 patients, and the regular forehead flap cover was used on four patients. While several flaps are listed for reconstruction, they found that nasolabial, VY development, and forehead flaps are the best options for most facial defects. It is possible to achieve excellent functional and cosmetic outcomes [9].

A multicenter retrospective study by Helmy et al., was performed on 254 patients. 175 cases were reconstructed by local flaps: Advancement flaps were operated in most of cases (117 cases), 25 patients were reconstructed by nasolabial flaps, and 33 patients were surgically treated by forehead flap. They stated that all flaps sensationally survived but the advancement flap has showed a superior aesthetic outcome [26].

Despite the fact that flap classification offers a clear understanding of flap properties, different reconstructive options necessitate a comprehensive approach to evaluate the facial defect. According to Patel and Sykes [27], the key points for facial reconstruction were chosen.

First, examination and analysis the facial defect, taking into account skin color, thickness, tissue composition, location, and subunits involved. If the defect affects more than half of the subunit, it is recommended that the entire subunit be resected, as this can improve the aesthetic outcome by hiding the incisions at the cosmetic subunits' borders [28].

Secondly, after the defect has been found, the reconstructive options should be evaluated using the reconstructive ladder in a graded manner. The simplest to most complex methods are secondary intension, primary closure, skin grafting, tissue expansion, local tissue transfer, distant tissue transfer, and free flap [29].

The surrounding anatomy must also be considered, as well as the appropriate areas of tissue recruitment and facial landmarks that cannot withstand distortion. Flaps should also be designed so that scars are contained within the relaxed skin tension lines and near parallel to the lines of maximum extensibility until the ideal areas for tissue recruitment have been selected. Finally, subunit boundary incisions should be made within the relaxed skin tension lines [30].

The incisions that precisely camouflaged within the limits of the facial aesthetic units as the flaps converge toward medial, either by advance, rotation, or interpolation, are the benefit offered by facial reconstruction based on aesthetic units.
Another benefit is that, once made, the incisions can be expanded to suit the needs while remaining within the limits of the facial aesthetic units. Finally, even before the stitches are applied, the aesthetic effects can be seen from the beginning [30].

This study has some limitations: Firstly, missing data due to its retrospective nature may lead to an incomplete understanding of defect or reconstructive characteristics. Also, few numbers of cases that collected. Prospectively designed studies that include validated patient-reported outcome instruments following reconstructions are essential to identify procedures, which optimize both patient satisfaction and surgical outcomes.

\section{Conclusion:}

Local flaps achieve the excellent outcomes and are the recommended choice for facial defects reconstruction. It is proved by its donor site availability, reliable vascularity, and subsequent form restoration. It is possible to obtain outstanding practical and aesthetic outcomes. Proper execution necessitates a high level of professional knowledge and experience. It is also essential to have a detailed knowledge of facial anatomy and aesthetics.

\section{Recommendations and messages:}

Reconstruction based on aesthetic units has the advantage of providing a natural, harmonic, and beautiful result after the excision of the skin cancer, giving the patient the possibility of reincorporating his/her daily activities in the quickest and most natural way possible, with the restoration of form and preservation of function without disfiguring scars in comparison with other types of reconstruction.

Conflict of interest: Non declared.

Source of funding: None.

\section{REFERENCES}

1- Kang K.W., Lee D.L., Shin H.K., Jung G.Y., Lee J.H. and Jeon M.S.: A Retrospective Clinical View of Basal Cell Carcinoma and Squamous Cell Carcinoma in the Head and Neck Region: A Single Institution's Experience of 247 Cases over 19 Years. Arch. Craniofac. Surg. Jun., 17 (2): 56-62, 2016.

2- Marzuka A.G and Book S.E.: Basal cell carcinoma: Pathogenesis, epidemiology, clinical features, diagnosis, histopathology, and management. Yale J. Biol. Med., Jun. 1; 88 (2): 167-79, 2015.

3- Welly Wijayanti and Khairuddin Djawad: Clinical study of basal cell carcinoma on the face: A 5-year retrospective study of 70 cases in a teaching hospital Surg Cosmet Dermatol. Rio de Janeiro v.12 n.3 jul-set. p. 222-9, 2020. 
4- Wu S., Han J., Vleugels R.A., Puett R., Laden F., Hunter D.J. and Qureshi A.A.: Cumulative ultraviolet radiation flux in adulthood and risk of incident skin cancers in women. Br. J. Cancer, Apr. 2; 110 (7): 1855-61, 2014.

5- Hakverdi S., Balci D.D., Dogramaci C.A., Toprak S. and Yaldiz M.: Retrospective analysis of basal cell carcinoma. Indian J. Dermatol. Venereol. Leprol., Mar-Apr. 77 (2): 251, 2011.

6- Rivers J.K., Mistry B.D., Hung T., Vostretsova K. and Mistry N.: A 13-Year Retrospective Study of Basal Cell Carcinoma in a Canadian Dermatology Practice: A Comparison Between Anatomical Location and Histopathologic Subtypes. J. Cutan Med. Surg., May 20 (3): 233-40, 2016.

7- Smith V. and Walton S.: Treatment of facial Basal cell carcinoma: A review. J. Skin Cancer, 1-7, 2011.

8- Hofer S.O. and Mureau M.A.: Improving outcomes in aesthetic facial reconstruction. Clin. Plast. Surg., Jul. 36 (3): 345-54, 2009.

9- Rao J.K. and Shende K.S.: Overview of Local Flaps of the Face for Reconstruction of Cutaneous Malignancies: Single Institutional Experience of Seventy Cases. J. Cutan Aesthet Surg., Oct-Dec. 9 (4): 220-25, 2016.

10- Choi J.H., Kim Y.J., Kim H., Nam S.H. and Choi Y.W.: Distribution of Basal cell carcinoma and squamous cell carcinoma by facial esthetic unit. Arch. Plast. Surg., Jul. 40 (4): 387-91, 2013.

11- Bertozzi N., Simonacci F., Greco M.P., Grignaffini E. and Raposio E.: Single center evidence for the treatment of basal cell carcinoma of the head and neck. Acta. Biomed., Jan. 22; 90 (1): 77-82, 2019.

12- Mancuso M., Gallo D., Leonardi S., Pierdomenico M., Pasquali E., De Stefano I., Rebessi S., Tanori M., Scambia G., Di Majo V., Covelli V., Pazzaglia S. and Saran A.: Modulation of basal and squamous cell carcinoma by endogenous estrogen in mouse models of skin cancer. Carcinogenesis, Feb. 30 (2): 340-7, 2009.

13- Cameron M.C., Lee E., Hibler B.P., Barker C.A., Mori S., Cordova M., Nehal K.S. and Rossi A.M.: Basal cell carcinoma: Epidemiology; pathophysiology; clinical and histological subtypes; and disease associations. J. Am. Acad. Dermatol., Feb. 80 (2): 303-317, 2019.

14- Betti R., Radaelli G., Bombonato C., Crosti C., Cerri A. and Menni S.: Anatomic location of Basal cell carcinomas may favor certain histologic subtypes. J. Cutan Med. Surg., Nov-Dec. 14 (6): 298-302, 2010.

15- Janjua O.S. and Qureshi S.M.: Basal cell carcinoma of the head and neck region: An analysis of 171 cases. J. Skin Cancer, 2012: 943472, 2012.

16- Buettner P.G. and Raasch B.A.: Incidence rates of skin cancer in Townsville, Australia. Int. J. Cancer, Nov. 23; 78 (5): 587-93, 1998.

17- Kim H.R., Na C.H., Shin B.S., et al.: A statistical study of cutaneous basal cell carcinoma and squamous cell carcinoma in Gwangju City and Chonnam Province (20062010). Korean J. Dermatol., 49: 1073-8, 2011.
18- Helmy Y., A. Taha, Abd EL-Nasser Khallaf and Abd ElFattah Al-Sheikh: "Survival and aesthetic outcome of local flaps used for reconstruction of face defects after excision of skin malignancies: Multi-institutional experience of 175 cases.” Int. J. Curr. Res. Med. Sci., 3 (5): 129-137, 2017.

19- Millard D.R.: Midline forehead skin flap. In: Berish S, editor. Grabb's Encyclopedia of Flaps. Vol. 1. Philadelphia, PA, USA: Lippincott Williams \& Wilkins, p. 99-100, 2009.

20- Bayer J., Schwarzmannová K., Dušková M., Novotná K., Kníže J. and Sukop A.: The nasolabial flap: The most versatile method in facial reconstruction. Acta. Chir. Plast. Spring, 59 (3-4): 135-141, 2018.

21- Furr M.C. and Wang T.D.: Complex local flap design in cheek reconstruction. Oper. Tech. Otolaryngol. Head Neck Surg., 22: 53-8, 2011.

22- Hayano S.M., Whipple K.M., Korn B.S. and Kikkawa D.O.: Principles of Periocular Reconstruction following Excision of Cutaneous Malignancy. J. Skin Cancer, 2012: 438502, 2012.

23- Egeler S.A., Johnson A.R., Ibrahim A.M.S., Bucknor A., Chen A., Malyar M., Tobias A.M., Lin S.J., Mureau M.A.M. and Lee B.T.: Reconstruction of Mohs Defects Located in the Head and Neck. J. Craniofac. Surg., Mar/ Apr. 30 (2): 412-417, 2019.

24- Russo F., Linares M., Iglesias M.E., Martínez-Amo J.L., Cabo F., Tercedor J., Costa-Vieira R., Toledo-Pastrana T., Ródenas J.M. and Leis V.: Reconstruction Techniques of Choice for the Facial Cosmetic Units. Actas Dermosifiliogr, Oct. 108 (8): 729-737, 2017.

25- van Leeuwen A.C., The A., Moolenburgh S.E., de Haas E.R. and Mureau M.A.: A Retrospective Review of Reconstructive Options and Outcomes of 202 Cases Large Facial Mohs Micrographic Surgical Defects, based on the Aesthetic Unit Involved. J. Cutan Med. Surg., Nov-Dec. 19 (6): 580-7, 2015.

26- Helmy Ali Y., Farahat Mohamed A., Nasef M.A., AbuElsoud A., Dahi A., Hossni M., Ouf M.O., Zayed T., ELBatawy A., Farid M., Taha Sayed A. and El-Banooby T.: Facial skin cancer reconstructive and cosmetic outcomes: Analysis with algorithm for its management. J. Cosmet Dermatol., May 19 (5): 1182-1190, 2020.

27- Patel K.G. and Sykes J.M.: Concepts in local flap design and classification. Operative Techniques in Otolaryngology - Head and Neck Surgery, Mar. 22 (1): 13-23, 2011.

28- Garritano F. and Fedok F.: Facial reconstruction after resection for cutaneous malignancies. Oper. Tech. Otolaryngol., 24: 36-44, 2013.

29- Dzwierzynski and William M.D.: Aesthetic Facial Reconstruction after Mohs Surgery, Plastic and Reconstructive Surgery: Sept., Vol. 140 - Issu. 3 - p 643, 2017.

30- Nunez Castaneda J.M. and Chang Grozo S.L.: Facial reconstruction according to aesthetic units. J. Cutan Aesthet. Surg., 13: 298-304, 2020. 